\title{
Synchronized lying in cattle in relation to time of day
}

\author{
Sophie Stoye ${ }^{\mathrm{a}, 1}$, Mason A. Porter ${ }^{\mathrm{b}}$, Marian Stamp Dawkins ${ }^{\mathrm{a}, *}$ \\ a Department of Zoology, University of Oxford, South Parks Road, Oxford OX2 8PW, UK \\ b Mathematical Institute, University of Oxford, 24-29 St. Giles', Oxford OX1 3LB, UK
}

\section{A R T I C L E I N F O}

\section{Article history:}

Received 26 January 2012

Received in revised form

12 April 2012

Accepted 26 June 2012

Keywords:

Cattle

Collective behaviour

Diurnal rhythm

Lying behaviour

Synchrony

Social facilitation

\begin{abstract}
A B S T R A C T
Postural synchrony, in which cattle lie down or stand up at the same time as other members of their herd, occurs both in animals housed indoors when enough resources are available and in those out at pasture, but the mechanisms by which such synchrony is achieved are poorly understood. We report a study of 6 groups of young cattle (Bos taurus) at pasture in which our aim was to study postural synchrony at different times of day and in relation to the postures of neighbouring cattle.

All of the observed groups exhibited a high degree of synchrony in lying/standing, as $70 \%$ of animals in a group exhibited the same posture over $93 \%$ of the time. Time of day had a significant effect $(P \approx 0.0046)$ : cattle were least synchronized in the middle of the day and most synchronized in the morning and evening. With the increasing use of synchrony of lying as a measure of welfare in cattle, such temporal effects need to be taken into account.

Cattle were more synchronized with the posture of a near neighbour than they were with that of a randomly chosen member of the herd $(P \approx 0.016)$, suggesting that cattle were actively synchronizing their postures with that of their neighbours. These results indicate that a full understanding of the mechanisms of postural synchronization in cattle herds will need to incorporate both collective (allelomimetic) and concurrent (individual) responses.
\end{abstract}

(c) 2012 Elsevier B.V. All rights reserved.

\section{Introduction}

Postural synchrony, in which cattle lie down or stand up at the same time as other members of their herd, is seen both in animals housed indoors when enough resources are available (Færevik et al., 2008; Gygax et al., 2007; Nielsen et al., 1997) and in those out at pasture (Benham, 1982), but the mechanisms underlying such synchrony are poorly understood (Estevez et al., 2007). There are at least two different ways in which synchrony might be achieved (Conradt and List, 2009; Gautrais et al., 2007). One is through collective behaviour

\footnotetext{
* Corresponding author. Tel.: +441865 271215.

E-mail address: marian.dawkins@zoo.ox.ac.uk (M. Stamp Dawkins).

${ }^{1}$ Present address: FAI (Food Animal Initiative) The Field Station, Wytham, Oxford OX2 8QJ, UK
}

of the herd, in which individual animals respond to the posture (lying or standing) of other animals by adopting the same posture themselves; this process is called "social facilitation" or "allelomimicry" (Clayton, 1978; Deneubourg and Goss, 1989). Eventually, as each animal adjusts its posture to be more like that of others, the entire group comes to behave synchronously (Sumpter, 2010). An alternative is through concurrent (sometimes called "combined") responses, in which each animal makes its own decision regarding when to lie down or stand up and does so at the same time as other animals because of external factors (such as the arrival or discovery of food) or internal factors (such as a similar need for food or similar daily rhythms). The daily synchronized 'rush hours' of human commuters exemplify how synchrony can result from concurrent responses. Although there is no collective decision to use the same roads at the 
same time, synchronized rush hours occur all over the world as a result of large numbers of people concurrently making the same independent decisions about when and where to travel.

The two mechanisms-collective behaviour and concurrent responses-are not mutually exclusive and can operate at the same time or even in conflict. For example, herds of Red Deer (Cervus elaphus) make collective decisions about when to feed and when to move, but individual animals also make concurrent decisions about when to feed based on their own nutritional requirements (Conradt, 1998). The conflict between collective synchrony with other animals and the differing nutritional requirements of males and females often leads to sufficient asynchrony in mixed-sex herds so that they become unstable and split into all-female and all-male groups that have more similar nutritional needs (Conradt, 1998; Conradt and Roper, 2000; Ruckstuhl and Neuhaus, 2002).

The factors leading to synchrony in cattle are likely to be similarly complex. However, although the socially facilitated collective behaviour of cattle has been studied in some detail (Dostalkova and Spinka, 2010; Ramseyer et al., 2009; Sarova et al., 2010), the effects of concurrent individual decisions on herd synchrony and their interactions with collective behaviour are not well known. In this paper, we report a preliminary study that examines the effects of both allelomimicry and time of day on synchrony within cattle herds out at pasture.

\section{Methods}

\subsection{Animals}

Six different groups of pastured cattle (Bos taurus) were observed on four different farms in Oxfordshire and Wiltshire in southern England. Animals were between 12 and 24 months of age, and the group sizes varied between 28 and 38. Table 1 summarises the ages, breeds, and sexes of each group.

\subsubsection{Observations}

All observations were made by a single observer (S. S.), who sat as unobtrusively as possible at a distance of $30-60 \mathrm{~m}$ from the nearest animal. To ensure that the behaviour of the cattle was affected as little as possible by the recording process, the observer arrived in the field approximately $20 \mathrm{~min}$ before the start of a session. This

Table 1

Description of the herds used in this study.

\begin{tabular}{|c|c|c|c|c|}
\hline $\begin{array}{l}\text { Group } \\
\text { no. }\end{array}$ & $\begin{array}{l}\text { Age } \\
\text { (months) }\end{array}$ & Breed & Sex & $\begin{array}{l}\text { Group } \\
\text { size }\end{array}$ \\
\hline 1 & $12-20$ & $\begin{array}{l}\text { Saler, Saler } \times \text { Hereford, } \\
\text { Saler } \times \text { Aberdeen Angus }\end{array}$ & $\mathrm{F}$ & 36 \\
\hline 2 & $15-20$ & Friesian-Holstein & $\mathrm{F}$ & 32 \\
\hline 3 & $12-18$ & Friesian-Holstein & $\mathrm{F}$ & 38 \\
\hline 4 & $20-24$ & $\begin{array}{l}\text { Hereford, Charolais, Aberdeen } \\
\text { Angus }\end{array}$ & $\mathrm{F}$ & 32 \\
\hline 5 & $20-24$ & $\begin{array}{l}\text { Hereford, Charolais, Aberdeen } \\
\text { Angus }\end{array}$ & M & 28 \\
\hline 6 & $20-23$ & Friesian-Holstein & $\mathrm{F}$ & 33 \\
\hline
\end{tabular}

allowed the cows to become accustomed to her presence prior to recording. Between recordings, the observer retreated to a location that offered a good view of the animals but was out of their lines of sight.

\subsubsection{Time-of-day effects}

Each group was observed for three sessions in one day: a morning session (06:00-09:00 h), a midday session (11:30-14:30 h), and an evening session (17:00-20:00 h). Readings were taken at 20-min intervals throughout each session, giving a total of 10 readings per session and 30 readings per day. Each recording day was in late August or early September (in 2010), and the days were as close together as possible to minimise changes in climate and in sunrise and sunset times. Additionally, we attempted to select days with similar weather forecasts (namely, dry and fairly warm) to try to ensure that the effects of temperature and rainfall were consistent.

\subsubsection{Allelomimetic effects.}

Each reading ( 10 per session) consisted of a scan sample count of the number of cows in the group who were standing up and the number who were lying down. A focal cow (R1) was selected at random (random numbers were taken from a Casio tx-85GT plus calculator), and its posture (standing or lying) was recorded. The postures of its nearest-neighbour (NN) cow and of another, randomly selected cow (R2) were also recorded. The identity of the NN cow was assessed by eye. (As the cows were well separated, there was no ambiguity about which was the nearest neighbour.) Random selection of individuals was achieved by viewing the herd through a grid of $8 \times 5$ squares drawn on a transparent A5 plastic sheet (Dawkins, 2007). The squares were labelled 1-40, and two lists of random numbers between 1 and 40 were generated using the random-number function on a calculator. The grid was then held up to the group in such a way that every individual could be seen through the plastic, and the top number of the first list was used to select a square on the grid. The cow closest to the top right-hand corner of that square was selected to be the focal cow (R1). The top number on the second list was then used in the same way to select the other random cow (R2).

\subsection{Statistical analysis}

\subsubsection{Measurements of synchrony}

We defined synchrony according to the percentage of animals simultaneously exhibiting the same posture (lying or standing). For each session, we compiled the number of readings (out of 10 ) in which the animals were recorded as showing the same or different postures. This gives 3 measurements of synchrony per day. As there is no consensus definition of 'synchrony', we analysed the data using five different possible thresholds (70, 80, 90, 95 , and $100 \%$ ) of synchronous posture.

\subsubsection{Time of day}

To examine the effect of time of day on synchrony, we used the 95\% threshold for synchrony and let the number of times that this was observed at different times of day 
be a dependent variable. The data were inspected and found to fulfil the conditions for analysis of variance, so we used a one-way ANOVA to test for significant departures from no difference with time of day (with 'herd' as the unit of replication). Because each herd was observed for only one day, we note that the replications cannot distinguish between 'herd' and 'day'.

\subsubsection{Nearest-neighbour versus randomly selected cow}

To determine whether cows were more synchronous with their nearest neighbours than with a randomly selected cow, we categorised the data into whether the randomly chosen cow (denoted R1) was showing the 'same' or 'different' posture as (a) his/her nearest neighbour and (b) the other randomly selected cow (denoted R2). The highest possible number of 'same' values was 30 , which would indicate that R1 was performing the same posture as NN or R2 during all recordings in that time period. For each herd, we counted the number of 'same' values out of 30 , so there was one value for $\mathrm{NN}$ and one for R2 for each herd. Since these data did not fulfil the conditions for parametric analysis, we then compared these values using a non-parametric Wilcoxon MatchedPairs test with the prediction that $\mathrm{NN}>\mathrm{R} 2$ for active synchronization with the nearest neighbour.

\section{Results}

\subsection{Degree of synchrony}

All herds exhibited a high degree of synchrony (see Table 2). There was synchrony at the $70 \%$ threshold $93.3 \%$ of the time, and this fell to $58.8 \%$ at the $100 \%$ threshold.

\subsection{Time of day}

The groups spent an average of over $70 \%$ of the time at or above the $95 \%$ threshold level (see Table 2 ), so we used this $95 \%$ threshold to examine the effect of time of day on synchrony. Although the herds were synchronous throughout the day, the degree of synchrony varied significantly with time of day $(F=5.56, \mathrm{df}=2,5$, $P=0.0046$, ANOVA). Herds were most synchronous in the evening (96.76\%), least synchronous in the middle of

Table 2

The number of readings per day (out of 30) when different percentages of cows in each group were observed showing the same posture (standing or lying).

\begin{tabular}{|c|c|c|c|c|c|}
\hline \multicolumn{6}{|c|}{ Synchrony threshold level } \\
\hline Group & $70 \%$ & $80 \%$ & $90 \%$ & $95 \%$ & $100 \%$ \\
\hline 1 & $27 / 30$ & $24 / 30$ & $18 / 30$ & $16 / 30$ & $14 / 30$ \\
\hline 2 & $29 / 30$ & $27 / 30$ & $26 / 30$ & $26 / 30$ & $21 / 30$ \\
\hline 3 & $30 / 30$ & $28 / 30$ & $26 / 30$ & $26 / 30$ & $22 / 30$ \\
\hline 4 & $28 / 30$ & $23 / 30$ & $17 / 30$ & $16 / 30$ & $13 / 30$ \\
\hline 5 & $25 / 30$ & $24 / 30$ & $22 / 30$ & $22 / 30$ & $21 / 30$ \\
\hline 6 & $29 / 30$ & $27 / 30$ & $25 / 30$ & $20 / 30$ & $15 / 30$ \\
\hline Mean \% & 93.3 & 85.0 & 74.4 & 70.0 & 58.9 \\
\hline
\end{tabular}

Table 3

The number of readings (out of 10) for each session in which a cow (R1) was recorded as showing the same posture (lying or standing) as a nearest neighbour (NN) or a randomly chosen cow (R2) in the same herd.

\begin{tabular}{|c|c|c|c|c|c|c|c|c|}
\hline Group & $\begin{array}{l}06: 00 \\
\text { NN }\end{array}$ & $\begin{array}{l}09: 00 \\
\text { R2 }\end{array}$ & $\begin{array}{l}11: 30 \\
\text { NN }\end{array}$ & $\begin{array}{l}14: 30 \\
R 2\end{array}$ & $\begin{array}{l}17: 00 \\
\text { NN }\end{array}$ & $\begin{array}{l}20: 00 \\
R 2\end{array}$ & $\begin{array}{l}\text { Daily } \\
\text { NN }\end{array}$ & $\begin{array}{l}\text { Totals } \\
\text { R2 }\end{array}$ \\
\hline 1 & 9 & 7 & 7 & 6 & 10 & 8 & 26 & 21 \\
\hline 2 & 10 & 7 & 9 & 9 & 10 & 10 & 29 & 26 \\
\hline 3 & 10 & 10 & 10 & 9 & 9 & 9 & 29 & 28 \\
\hline 4 & 9 & 8 & 8 & 7 & 10 & 9 & 27 & 24 \\
\hline 5 & 10 & 10 & 9 & 7 & 10 & 10 & 29 & 27 \\
\hline 6 & 10 & 9 & 8 & 7 & 10 & 10 & 28 & 26 \\
\hline
\end{tabular}

the day (89.47\%), and had an intermediate degree of synchrony in the morning (92.65\%).

\subsection{Synchrony between nearest neighbour versus randomly selected cow}

In Table 3, we show the numbers of readings in which the focus cow (R1) exhibited the same posture as its nearest neighbour (NN) and the same posture as a randomly chosen cow (R2). In none of the sessions for any of the herds was the posture of the focus cows more similar to randomly chosen cows than it was to nearest neighbours. It was the same on 7 of 18 occasions. Using the daily totals for each herd, the posture of cows was significantly more similar to a nearest neighbour than to a randomly chosen member of the same herd $\left(T^{+}=21\right.$, $n=6, P \approx 0.016$ one-tailed and $P \approx 0.032$ two-tailed Wilcoxon Matched-Pairs test).

\section{Discussion}

A high level of synchrony in lying and standing was recorded across all groups and for all times of day, as almost $60 \%$ of recording sessions showed $100 \%$ synchrony - that is, all of the animals in the herd were either lying down or were standing. On over 93\% of occasions, herds were at least $70 \%$ synchronous. The fact that the groups were $100 \%$ in synchrony nearly $60 \%$ of the time is very good evidence for the existence of synchrony in free-ranging groups of cattle. This agrees with the results of Benham (1982). We also found that the degree of synchrony varied with time of day, as cattle were most synchronous in the morning and evening and least synchronous in the middle of the day. Most previous studies on cattle synchrony have been done on dairy cows, for which milking and feeding times artificially synchronize the behaviour of herds (see e.g. Arave and Albright, 1976; Cooper et al., 2008; Langford et al., 2011). By contrast, the present study demonstrates that the degree of synchrony varies with the time of day even without these confounding factors. Dawn and dusk occurred during the observation periods, and this could have contributed to the observed synchrony.

This finding is particularly important in view of the fact that synchrony of lying is increasingly being used as a way of assessing cattle welfare (Fregonesi and Leaver, 
2001; Færevik et al., 2008; Napolitano et al., 2009; O'Driscoll et al., 2008) on the grounds that synchrony indicates that there are sufficient resources available for all individuals (Færevik et al., 2008). Where the resources are not sufficient-for example, if there is not enough room for all animals to lie down simultaneously - this can result in increased lameness in subordinate animals that are forced to stand (Galindo and Broom, 2000). EU welfare regulations now stipulate that cattle housed in groups should be given sufficient space to allow synchronous lying (Council of the European Union, 1997). If synchrony is to be used as a welfare indicator, then it is clear that synchrony needs be measured at multiple times in a day, as the results might be different at different times (Robert et al., 2011).

Cattle appear to synchronize their lying more with their nearest neighbours than with a random member of the herd, even in circumstances in which the herd is stationary and individuals would appear to have a free choice over when to lie down and when to stand up and graze. Cows thus behave like weakly coupled oscillators (Sun et al., 2011) and the observed synchrony is at least partly due to collective (allelomimetic) behaviour (Gautrais et al., 2007).

\section{Conclusions}

Cattle at pasture are highly synchronized in their lying behaviour, but the degree of synchrony varies with time of day. If synchrony of lying is used as a measure of welfare in cattle, then time of day needs to be taken into account.

Cattle show more postural similarity with their nearest neighbours than with a random member of the herd, suggesting that postural synchronization of the herd includes active allelomimetic behaviour as well as concurrent feeding and lying cycles.

\section{Conflict of interest statement}

None declared.

\section{Acknowledgements}

We would like to thank FAI (Food Animal Initiative), $\mathrm{H}$. Browning (Eastbrook Farm), P. Allen (Manor Farm), and W.A. Barnett for allowing observations (by S.S.) of their cattle.

\section{References}

Arave, C.W., Albright, J.L., 1976. Social rank and physiological traits of dairy cows as influenced by changing group membership. J. Dairy Sci. 59, 974-981.
Benham, P.F.J., 1982. Synchronisation of behaviour in grazing cattle. Appl. Anim. Ethol. 8, 403-404.

Clayton, D.A., 1978. Socially facilitated behaviour. Q. Rev. Biol. 53, 373-392.

Conradt, L., 1998. Could asynchrony in activity between the sexes cause inter-sexual social segregation in ruminants? Proc. R. Soc. Lond. B 265, 1359-1363.

Conradt, L., Roper, T.J., 2000. Activity synchrony and social cohesion: a fission-fusion model. Proc. R. Soc. Lond. B 267, 2213-2218.

Conradt, L., List, C., 2009. Group decisions in humans and animals: a survey. Philos. Trans. R. Soc. B 364, 719-742.

Cooper, M.D., Amey, D.R., Webb, C.R., Phillips, C.J., 2008. Interactions between housed dairy cows feeding lying and standing. J. Vet. Behav. Clin. Appl. Res. 3 (5), 218-227.

Council of the European Union, 20 January 1997. Council Directive 97/2/EC. $\langle$ http://ec.europa.eu/food/fs/aw/aw_legislation/calves/97-2-ec_en.pdf $\rangle$.

Dawkins, M.S., 2007. Observing Animal Behaviour. Oxford University Press, Oxford.

Deneubourg, J.-L., Goss, S., 1989. Collective patterns and decisionmaking. Ethol. Ecol. Evol. 1, 295-311.

Dostalkova, I., Spinka, M., 2010. When to go with the crowd: modeling synchronization of all-or-nothing activity transitions in grouped animals. J. Theor. Biol. 263, 437-448.

Estevez, I., Andersen, I.L., Nævdal, E., 2007. Group size, density and social dynamics in farm animals. Appl. Anim. Behav. Sci. 103, 185-204.

Færevik, G., Tjentland, K., Løvik, S., Andersen, I.L., Bøe, K.E., 2008. Resting pattern and social behaviour of dairy calves housed in pens with different sized lying areas. Appl. Anim. Behav. Sci. 114, 54-64.

Fregonesi, J.A., Leaver, J.D., 2001. Behaviour, performance and health indicators of welfare for dairy cows housed in strawyard or cubicle systems. Livest. Prod. Sci. 94, 205-216.

Galindo, F., Broom, D.M., 2000. The relationship between social behaviour of dairy cows and occurrence of lameness in 3 herds. Res. Vet. Sci. 69, 75-79.

Gautrais, J., Michelina, P., Sibbald, A., Bon, R., Deneubourg, J.-L., 2007. Allelomimetic synchronization in Merino sheep. Anim. Behav. 74, 1443-1454.

Gygax, L., Mayer, C., Westerath, H.S., Friedli, K., Wechsler, B., 2007. Onfarm assessment of the lying behaviour of finishing bulls kept in housing systems with different floor qualities. Anim. Welfare 16, 205-208.

Langford, F.M., Rutherford, K.M.D., Sherwood, L., Jack, M.C., Lawrence, A.B., Haskell, M.J., 2011. Behaviour of cows during and after peak feeding time on organic and conventional dairy farms in the United Kingdom. J. Dairy Sci. 94, 746-753.

Napolitano, F., Knierem, U., Grasso, F., De Rosa, G., 2009. Positive indicators of cattle welfare and their applicability to on-farm protocols. Ital. J. Anim. Sci. 8, 355-365.

Nielsen, L.H., Mogensen, L., Krohn, C., Hindhede, J., 1997. Resting and social behaviour of dairy heifers housed in slatted floor pens with different sized bedded lying areas. Appl. Anim. Behav. Sci. 54, 307-316.

O’Driscoll, K., Hanlon, A., Boyle, L., 2008. The effect of out-wintering pad design on the synchrony of dairy cow behaviour. J. Dairy Sci. 91, 4651-4660.

Ramseyer, A., Thierry, B., Boissy, A., Dumont, B., 2009. Decision-making processes in group departures of cattle. Ethology 15, 948-957.

Robert, B.D., White, B.J., Renter, D.G., Larson, R.L, 2011. Determination of lying behavior patterns in healthy beef cattle by use of wireless accelerometers. Am. J. Vet. Res. 72, 467-473.

Ruckstuhl, K.E., Neuhaus, P., 2002. Sexual segregation in ungulates: a comparative test of three hypotheses. Biol. Rev. 77, 77-96.

Sarova, R., Spinka, M., Panama, J.L.A., Simecek, P., 2010. Graded leadership by dominant animals in a herd of female beef cattle. Anim. Behav. 79, 1037-1045.

Sumpter, D.J.T., 2010. Collective Animal Behavior. Princeton University Press, Princeton.

Sun, J., Bollt, E.M., Porter, M.A., Dawkins, M.S., 2011. A mathematical model for the dynamics and synchronization of cows. Physica D 240 (19), 1497-1509. 